\title{
Pengaruh Permainan Tradisional Terhadap Hasil Belajar Lompat Jangkit
}

\author{
The Effect Of Traditional Games On The Results Of Jumping Learning
}

\author{
Agus Santosa \\ STKIP Pasundan, Cimahi, Jawa Barat, Indonesia \\ Agussantosa13@gmail.com
}

\begin{abstract}
Abstrak
Tujuan penelitian ini untuk mengetahui seberapa besar pengaruh permainan tradisional terhadap hasil belajar lompat jangkit pada siswa di SMK TI Garuda Nusantara Kota Cimahi. Metode Penelitian yang digunakan dalam penelitian ini adalah Metode Eksperimen, dengan desain penelitian yang digunakan adalah "One Group Pre Test Post Test". Populasi peneletian ini adalah siswa SMK TI Garuda Nusantara kelas XI berjumlah 30 siswa. Teknik Sampling yang digunakan adalah Total Sampling. Maka sample dalam penelitian ini berjumlah 30 siswa. Hasil perhitungan data dari 30 siswa maka nilai rata-rata 4,65, nilai maksimal 5,32, nilai minimal 4,11, standar deviasi 0,30, variansi 0,09, simpangan baku 0,24 . Hasil data analisis menunjukan $t_{\text {hitung }}$ lebih kecil dari $t_{\text {tabel }}$ sebesar 10,789 > 1.662 dan memiliki nilai Sig-nya sebesar 0,00 lebih kecil dari 0,05. Hal ini menunjukkan bahwa pengujian ini mendukung hipotesis Ha diterima dengan $t_{\text {hitung }}$ lebih besar dari $\mathrm{t}_{\text {tabel}}$, dengan nilai 10,789 > 1.662 akibatnya Permainan Tradisional berpengaruh positif terhadap Hasil Belajar Lompat Jangkit.
\end{abstract}

Kata Kunci: Permainan Tradisional, Hasil Belajar, Lompat jangkit.

\begin{abstract}
The purpose of this study is to find out how much influence traditional games have on the learning outcomes of infectious jumps in students at TI Garuda Nusantara Vocational School, Cimahi City. The research method used in this study is the Experimental Method, with the research design used is "One Group Pre Test Post Test". The population of this research is the students of Garuda Nusantara IT Vocational School in class XI totaling 30 students. The sampling technique used is total sampling. So the sample in this study amounted to 30 students. The results of the calculation of the data from 30 students then the average value of 4.65, a maximum value of 5.32, a minimum value of 4.11, a standard deviation of 0.30, a variance of 0.09, a standard deviation of 0.24. The results of the analysis data show that tcount is smaller than t table of 10,789> 1,662 and has a Sig value of 0.00 less than 0.05. This shows that this test supports the Ha hypothesis accepted with tcount greater than $t$ table, with the value of 10,789> 1,662 as a result Traditional Games have a positive effect on the Outbreak Jump Learning Outcomes.
\end{abstract}

Keywords: Traditional games, learning Outcomes, Infectious Jumps 


\section{PENDAHULUAN}

Dalam dunia pendidikan di Indonesia proses pembelajaran kurang begitu maksimal yang menjadi faktor bisa dari guru ataupun dari siswa itu sendiri tergantung faktor lingkungan yang mempengaruhinya. Misalkan dalam pelajaran pendidikan jasmani siswa kurang semangat dan dalam materi kecabangan olahraga atletik nomor lompat jangkit hasil yang diperoleh siswa kurang maksimal dalam melakukan lompatan oleh karena itu dalam proses pembelajaran ini dibutuhkan adanya kreatifitas dan inovasi dari guru sebagai pendidik. Kemudian tidak hanya faktor intern saja melainkan faktor ekstern, yaitu kemajuan teknologi, kemajuan teknologi ini menyebabkan seseorang malas bergerak, apalagi dengan adanya permainan dalam genggaman tangan, seperti Handphone, Playstation, Tablet inilah yang menyebabkan seseorang malas untuk bergerak. Maka dengan adanya suatu inovasi dalam proses pembelajaran seperti memasukan unsur permainan dalam PBM, misalnya permainan tradisional ke dalam proses pembelajaran dapat dijadikan sebagai solusi dalam permasalahan yang ada..

Permainan tradisional ialah aktivitas budaya dalam bentuk permainan dengan unsur-unsur gerak, seni, sosial, dan budaya. Menurut Ni Kd, dkk (2014) "Sebagai aktivitas budaya, permainan itu mengandung sumber dan media informasi yang dapat mewarnai dan dapat memperkaya kebudayaan nasional maupun daerah, serta pengukuh nilai-nilai budaya yang dapat merangsang ke arah pembaharuan yang kreatif. Menurut Slameto (2003 : 2), Belajar ialah suatu proses usaha yang dilakukan seseorang untuk memperoleh suatu perubahan tingkah laku yang baru secara keseluruhan, sebagai hasil pengalamannya sendiri dalam interaksi dengan lingkungannya. "Belajar merupakan proses terbentuknya tingkah laku baru yang disebabkan individu merespon lingkungannya, melalui pengalaman pribadi yang tidak termasuk kematangan, pertumbuhan atau instink. Belajar sebagai proses akan terarah kepada tercapainya tujuan (goal oriented) dari pihak siswa maupun dari pihak guru.

Gerakan lompat jangkit memproyeksikan pusat gaya berat tubuh si pelompat di udara ke arah depan dengan melalui tiga tahapan lompatan atau tumpuan, yaitu Hop-Step-Jump. Menurut ketentuan, si pelompat harus melakukan tiga kali menumpu, menumpu dua kali dengan kaki yang sama yang disebut step, dan diakhiri dengan gerakan jump atau lompat. Hasil dari suatu lompatan sangat bergantung pada kecepatan horizontal dan kekuatan pada ketiga tahapan tumpuan tersebut. Jarak antara hop, step, dan jump bervariasi bergantung pada kecepatan, kekuatan, dan kelentukan otot. Sudut tumpuan yang tepat sangat membantu menjaga kecepatan. Penulis menyadari ada beberapa faktor yang menumbuhkan peningkatan hasil belajar lompat jangkit dalam mengikuti pelajaran penjas salah satunya permainan tradisional. 
Berdasarkan pemaparan di atas peneliti mencoba untuk mengatasi masalah yang ada yaitu kurangnya hasil yang maksimal dalam belajar lompat jangkit dengan memasukan unsur permainan tradisional karena permainan tradisional bisa memberikan kesenangan terhadap siswa selain itu permainan tradisional bisa dijadikan bahan untuk menguasai lompat jangkit. Oleh karena itu peneliti berharap dapat meningkatkan hasil belajar lompat jangkit dengan memasukan permainan tradisional di dalam pembelajaran pendidikan jasmani.

\section{METODE PENELITIAN}

Metode yang digunakan dalam penelitian ini adalah Metode Eksperimen, dengan desain penelitian yang digunakan adalah “One Group Pre Test Post Test”. Populasi peneletian ini adalah siswa SMK TI Garuda Nusantara kelas XI berjumlah 30 siswa. Teknik Sampling yang digunakan adalah Total Sampling. Maka sample dalam penelitian ini berjumlah 30 siswa. Untuk menjawab atau menguji hipotesis yang telah dikemukakan maka data berupa nilai yang sudah direkap dan sudah lengkap, selanjutnya dihitung menggunakan pendekatan statistika menggunakan program SPSS versi 22.

\section{HASIL DAN PEMBAHASAN}

\section{Hasil}

Penelitian ini merupakan penelitian eksperimen yang dilaksanakan di SMK TI Garuda Nusantara Kota Cimahi, sampel yang digunakan dalam penelitian adalah kelas XI TKJ berjumlah 30 siswa, sebelum diberi perlakuan semua siswa (sampel) terlebih dahulu diberi tes awal (Pre-test) untuk mengetahui sejauh mana keterampilan lompat jangkit yang dimiliki oleh semua siswa. Hasil nilai dari pre-test tersebut dibandingkan dengan nilai hasil dari post test. Setelah pre-test, kemudian semua siswa diberi perlakuan Permainan Tradisional berupa Permainan Tradisional Engklek, Permainan Tradisional Perepet Jengkol, Permainan Tradisional Bebentengan, Permainan Tradisional Galah Asin. Datanya kemudian dianalisis dan diinterpretasikan guna memecahkan masalah penelitian, apakah ada pengaruh terhadap hasil pembelajaran atau tidak. Hasil analisis dan pembahasannya diuraikan sebagai berikut : 
Tabel 1. Hasil tes awal dapat dilihat pada tabel sebagai berikut :

\begin{tabular}{|c|c|c|c|}
\hline \multirow{2}{*}{ No Urut } & \multirow{2}{*}{ Nama Siswa } & \multicolumn{2}{|c|}{ Jarak Lompatan (meter) } \\
\hline & & Pre Test & Post Test \\
\hline 1 & Acep & 4,43 & 4,71 \\
\hline 2 & Adit & 4,62 & 4,75 \\
\hline 3 & Alice & 4,31 & 4,61 \\
\hline 4 & Bagas & 4,55 & 4,64 \\
\hline 5 & Bastian & 4,46 & 4,77 \\
\hline 6 & Cucu & 4,19 & 4,55 \\
\hline 7 & Dandi & 4,77 & 4,86 \\
\hline 8 & Daniel & 4,83 & 5,01 \\
\hline 9 & Dery & 4,66 & 4,98 \\
\hline 10 & Fadilah & 4,68 & 4,99 \\
\hline 11 & Febiana & 4,27 & 4,87 \\
\hline 12 & Febrian & 4,46 & 4,69 \\
\hline 13 & Firman & 4,51 & 4,71 \\
\hline 14 & Hildan & 4,99 & 5,21 \\
\hline 15 & Ichsan & 4,72 & 5,25 \\
\hline 16 & Istria & 4,56 & 5,12 \\
\hline 17 & Junaedi & 4,32 & 4,82 \\
\hline 18 & Kiki & 4,12 & 4,73 \\
\hline 19 & Mamat & 4,23 & 4,74 \\
\hline 20 & Mochamad Ferdyansah & 4,34 & 4,86 \\
\hline 21 & Muhammad Aldi & 4,45 & 4,91 \\
\hline 22 & Muhamad Nur Zaman & 4,81 & 5,31 \\
\hline 23 & Muhamad Sayuti & 4,19 & 4,74 \\
\hline 24 & Nur Ikhsan Hidayat & 4,23 & 4,68 \\
\hline 25 & Reza & 4,21 & 4,55 \\
\hline 26 & Rizky & 4,11 & 4,49 \\
\hline 27 & Rohmat & 4,69 & 4,96 \\
\hline 28 & Septi & 4,31 & 5,32 \\
\hline 29 & Yoga & 4,16 & 4,88 \\
\hline 30 & M. Alfian & 4,66 & 4,98 \\
\hline & $\sum$ & & 279,53 \\
\hline & Rata-Rata (X) & & 4,65 \\
\hline & Nilai Max & & 5,32 \\
\hline & Nilai Min & & 4,11 \\
\hline & Standar Deviasi & & $\mathbf{0 , 3 0}$ \\
\hline & Variansi & & 0,09 \\
\hline & Simpangan Baku & & 0,24 \\
\hline
\end{tabular}

\section{Pengujian Persyaratan Analisis Data}

Dari hasil penelitian yang telah dilakukan bahwa pengaruh dari metode permainan tradisional ternyata memberikan hasil yang baik dalam upaya meningkatkan kemampuan lompat jangkit. Karena lompat jangkit merupakan suatu cabang olahraga yang membutuhkan daya tolak yang kuat dari otot-otot tungkai, untuk itu pemberian latihan haruslah sesuai dengan prinsip latihan yang ditetapkan, agar hasil maksimal dapat dicapai.

Uji Normalitas adalah sebuah uji yang dilakukan dengan tujuan untuk menilai sebaran data pada sebuah kelompok data atau variabel, apakah sebaran data tersebut berdistribusi normal atau tidak (Sugiyono, 2014). 
Tabel 2. Uji Normalitas

\begin{tabular}{|l|r|r|r|r|r|}
\hline \multicolumn{7}{|c|}{ Descriptive Statistics } \\
\hline & N & Minimum & Maximum & Mean & Std. Deviation \\
\hline Pretest & 30 & 4,11 & 4,99 & 4,4613 &, 24139 \\
\hline Posttest & 30 & 4,49 & 5,32 & 4,8563 &, 22368 \\
\hline Valid N (listwise) & 30 & & & & \\
\hline
\end{tabular}

\section{Hasil Pengujian Hipotesis}

Uji Homogenitas adalah pengujian mengenai sama tidaknya variansi-variansi dua buah distribusi atau lebih. Uji homogenitas biasanya digunakan sebagai syarat dalam analisis independen sample T Tes dan Anova. Dasar Pengambilan Keputusan :

- Jika nilai Signifikansi > 0,05, maka distribusi data adalah homogen.

- Jika nilai Signifikansi < 0,05, maka distribusi data adalah tidak homogen.

Tabel 3. Uji Homogenitas

\begin{tabular}{|l|r|r|r|r|r|}
\hline & Sum of Squares & Df & Mean Square & F & \multicolumn{1}{c|}{ Sig. } \\
\hline Between Groups & 1,593 & 24 & 0,066 & 3,434 & 0,087 \\
\hline Within Groups & 0,097 & 5 & 0,019 & & \\
\hline Total & 1,690 & 29 & & & \\
\hline
\end{tabular}

Jadi kesimpulannya adalah hasil dari uji homogenitas pre test yaitu 0,087 maka lebih besar dari 0,05 sehingga distribusi data adalah homogen.

\section{Tabel 4. Uji T}

\begin{tabular}{|c|c|c|c|c|c|c|c|c|c|}
\hline \multicolumn{7}{|c|}{ Paired Differences } & \multirow[b]{3}{*}{$\mathrm{T}$} & \multirow[b]{3}{*}{$\mathrm{df}$} & \multirow[b]{3}{*}{ Sig. (2-tailed) } \\
\hline & & \multirow[b]{2}{*}{ Mean } & \multirow{2}{*}{$\begin{array}{c}\text { Std. } \\
\text { Deviatio } \\
\mathrm{n}\end{array}$} & \multirow{2}{*}{$\begin{array}{c}\begin{array}{c}\text { Std. Error } \\
\text { Mean }\end{array} \\
\end{array}$} & \multicolumn{2}{|c|}{$\begin{array}{l}\text { 95\% Confidence } \\
\text { Interval of the } \\
\text { Difference }\end{array}$} & & & \\
\hline & & & & & Lower & Upper & & & \\
\hline & $\begin{array}{l}\text { Pretest \& } \\
\text { Post Test }\end{array}$ &,- 39500 & ,20053 & ,03661 &,- 46988 &,- 32012 & 10,789 & 29 & 0,00 \\
\hline
\end{tabular}

Berdasarkan pada tabel uji t diatas, untuk mengetahui besarnya masing-masing variabel terlihat bahwa $t_{\text {hitung }}$ adalah 10,789 sedangkan $t_{\text {tabel }}$ bisa dihitung pada tabel $t$-test, dengan $\alpha=0.05$ dan $\mathrm{df}=29$ didapat $\mathrm{t}_{\text {tabel }}$ adalah 1.662 .

Hasil pengujian (uji t) Pengaruh Permainan Tradisional Terhadap Hasil Belajar Lompat Jangkit di Kota Cimahi menunjukan thitung lebih kecil dari tabel sebesar 10,789 > 1.662 dan memiliki nilai signya sebesar 0,00 lebih kecil dari 0,05. Hal ini menunjukkan bahwa pengujian ini 
mendukung hipotesis Ha diterima dengan $t_{\text {hitung }}$ lebih besar dari $t_{\text {tabel }}$, dengan nilai 10,789> 1.662 akibatnya Permainan Tradisional berpengaruh positif terhadap Hasil Belajar Lompat Jangkit.

\section{Pembahasan}

Berdasarkan hasil penelitian tersebut menunjukan bahwa permainan tradisional memberikan pengaruh yang signifikan terhadap hasil belajar lompat jangkit pada siswa kelas XI TKJ di SMK TI Garuda Nusantara Kota Cimahi.

Hasil pengujian (uji t) Pengaruh Permainan Tradisional Terhadap Hasil Belajar Lompat

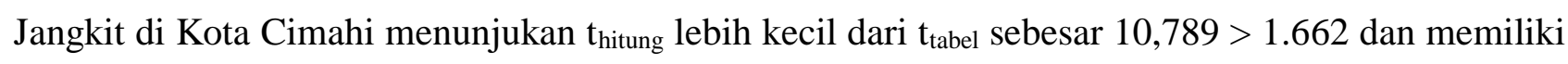
nilai signya sebesar 0,00 lebih kecil dari 0,05. Hal ini menunjukkan bahwa pengujian ini mendukung hipotesis Ha diterima dengan $t_{\text {hitung }}$ lebih besar dari $t_{\text {tabel }}$, dengan nilai 10,789>1.662 maka Permainan Tradisional berpengaruh positif terhadap Hasil Belajar Lompat Jangkit. Melalui permainan tradisional, siswa diajarkan untuk melatih keseimbangannya dan siswa juga diajak mengenal permainan tradisional di era digital. Oleh karena itu pendidik dituntut lebih kreatif dalam menciptakan suasana belajar yang menyenangkan dengan cara mengenalkan budaya, memanfaatkan dan mengkreasikan bahan yang ada dilingkungan sekitar dan dengan memperhatikan bahwa siswa di sekolah ataupun manusia itu adalah makhluk bermain atau homoludens. Seperti yang dikemukakan Huizinga (1950), Homo Ludens adalah sebuah konsep yang memahami bahwa manusia merupakan seorang pemain yang memainkan permainan. Homo ludens sendiri merupakan sebuah konsep yang muncul atau ditemukan dalam kebudayaan. Kemudian dengan diperkenalkan kembali dengan maksud dapat menumbuhkan minat anak mencintai permainan tradisional.

Dengan menerapkan permainan tradisional akan menempatkan siswa sebagai subjek pembelajaran dan tidak lagi dipandang sebagai penerima pasif tetapi siswa diberikan kesempatan untuk mengembangkan psikomotor, kognitif dan afektifnya. Seperti yang kemukakan pula oleh Misbach (2006:7) dalam penelitiannya menunjukkan bahwa permainan tradisional dapat menstimulasi berbagai aspek perkembangan anak yang dapat meliputi hal-hal sebagai berikut. a) Aspek motorik dengan melatih daya tahan, daya lentur, sensorimotorik, motorik kasar, dan motorik halus, b)Aspek kognitif dengan mengembangkan imaginasi, kreativitas, problem solving, strategi, kemampuan antisipatif, dan pemahaman kontekstual, c) Aspek emosi dengan menjadi media katarsis emosional, dapat mengasah empati dan pengendalian diri, d) Aspek bahasa berupa pemahaman konsep- konsep nilai, d) Aspek sosial dengan mengkondisikan anak agar dapat menjalin relasi, bekerjasama, melatih kematangan sosial dengan teman sebaya dan meletakkan pondasi untuk melatih keterampilan sosialisasi dengan berlatih peran dengan orang yang lebih dewasa dan masyarakat secara umum, e) Aspek spiritual, permainan tradisonal dapat membawa anak untuk menyadari keterhubungan dengan sesuatu yang bersifat Agung (transcendental), f) 
Aspek ekologis dengan memfasilitasi anak untuk dapat memahami pemanfaatan elemen-elemen alam sekitar secara bijaksana, dan g) Aspek nilai-nilai/moral dengan memfasilitasi anak untuk dapat menghayati nilai-nilai moral yang diwariskan dari generasi terdahulu kepada generasi selanjutnya. Maka dapat disimpulkan dari beberapa pendapat di atas, dengan permainan tradisional disini banyak terjadi interaksi dengan teman, aturan permainan yang dapat membentuk suatu karakter siswa itu sendiri.

\section{KESIMPULAN}

Berdasarkan hasil pengolahan dari analisis data yang telah dilakukan mengenai pengaruh permainan tradisional terhadap hasil belajar lompat jangkit siswa di SMK TI Garuda Nusantara Cimahi. Maka penulis menyimpulkan hasil penelitian yaitu :

Hasil perhitungan data dari 30 siswa maka nilai rata-rata 4,65, nilai maksimal 5,32, nilai minimal 4,11, standar deviasi 0,30, variansi 0,09, simpangan baku 0,24.

Hasil data analisis menunjukan $t_{\text {hitung }}$ lebih kecil dari $t_{\text {tabel }}$ sebesar 10,789>1.662 dan memiliki nilai signya sebesar 0,00 lebih kecil dari 0,05 . Hal ini menunjukkan bahwa pengujian ini mendukung hipotesis Ha diterima dengan $t_{\text {hitung }}$ lebih besar dari $t_{\text {tabel }}$, dengan nilai 10,789>1.662 artinya bahwa Permainan Tradisional berpengaruh positif terhadap Hasil Belajar Lompat Jangkit.

\section{Saran}

Berdasarkan kesimpulan yang telah peneliti kemukakan ada beberapa hal yang dapat disampaikan sebagai saran dan masukan sebagai berikut :

$>$ Bagi Guru

Seorang guru diharapkan harus lebih memperhatikan dan memberikan pemahanan khususnya dalam bidang atletik lompat jangkit agar bisa lebih dikembangkan dengan lebih baik lagi. Timbulnya inisiatif dari pihak sekolah maupun dari guru pendidikan jasmani untuk memberi pengaruh kepada siswa di sekolah.

$>$ Bagi Siswa

Siswa hendaknya menanamkan jiwa melestarikan permainan tradisional dan rasa percaya diri agar termotivasi dalam mengikuti kegiatan atletik lompat jangkit di SMK TI Garuda Nusantara Cimahi. Juga sebagai sarana prestasi para siswa dalam bidang olahraga.

\section{$>$ Bagi Lembaga Sekolah}

Hendaknya di lingkungan sekolah harus mewajibkan para siswa untuk mengikuti kegiatan atletik lompat jangkit sebagai salah satu pembentukan karakter dan sikap disiplin bagi siswa.

\section{$>$ Bagi Peneliti}

Bagi peneliti hendaknya mengadakan penelitian yang sama, agar untuk mengkaji aspekaspek lain agar diperoleh hasil yang lebih optimal. 


\section{Implikasi}

Berdasarkan hasil penelitian dengan hasil yang diperoleh yaitu pengaruh permainan tradisional terhadap hasil belajar lompat jangkit yang dikatakan positif signifikan. Penelitian ini semoga bermanfaat bagi guru olahraga atau guru di sekolah, untuk lebih memahami karakteristik para siswa khususnya yang mengikuti kegiatan atletik lompat jangkit agar senantiasa dikembangkan dan ditingkatkan agar tujuan dari pengaruh permainan tradisional dapat lebih luas perkembangannya. Diharapkan penelitian ini juga bisa bermanfaat atau sebagai acuan di masa yang akan datang.

\section{DAFTAR PUSTAKA}

Johan Huizinga. (1950). Homo Ludens: A Study of The Play Element in Culture. London: Roy Publishers.

Misbach, I. (2006). Peran Permainan Tradisional yang Bermuatan Edukatif dalam Menyumbang Pembentukan Karakter dan Identitas Bangsa. Laporan Penelitian. Bandung: Universitas Pendidikan Indonesia. Tidak diterbitkan

Ni Kd, et al. (2014). Penerapan Permainan Tradisonal Engklek Untuk Mengembangkan Motorik Kasar Anak Kelompok A TK Raisma Putra Denpasar. Jurnal, Universitas Pendidikan Ganesha Singaraja.

Slameto,. (2003). Belajar. Jakarta: Rineka Cipta.

Sugiyono. (2014). Metode Penelitian Pendidikan Pendekatan Kualitatif, Kuantitatif, dan R\&D.

Bandung: Alfabeta. 